\title{
Randomised, double blind comparison of omeprazole and cimetidine in the treatment of symptomatic gastric ulcer
}

\author{
C M BATE, S P WILKINSON, G V H BRADBY, M C BATESON, \\ W S HiSlOP, J P CROWE, C P WILlOUGHBY, E M PEERS, \\ AND P D I RICHARDSON
}

From the Royal Albert Edward Infirmary, Wigan; Gloucestershire Royal Hospital, Gloucester; Sandwell District General Hospital, W Bromwich; The General Hospital, Bishop Auckland; Royal Alexandra Hospital, Paisley: Mater Misericordiae Hospital, Dublin; Basildon Hospital, Basildon; Astra Pharmaceuticals Ltd, Kings Langley, Herts

SUMMARY In a randomised, double blind, parallel group study in patients with symptomatic gastric ulcer $(94 \% \geq 5 \mathrm{~mm}$ diameter), 102 received omeprazole $20 \mathrm{mg}$ om and 87 cimetidine $400 \mathrm{mg}$ bd. After four weeks $73 \%$ and $58 \%(p<0.05)$ respectively had healed (eight weeks: $84 \%$ and $75 \%$, ns). After four weeks, a greater proportion $(81 \%)$ of omeprazole treated patients was symptom free than of those receiving cimetidine $(60 \% ; p<0 \cdot 01)$. Over the first two weeks, patients receiving omeprazole had less day pain, less night pain and took fewer antacids than those receiving cimetidine (all $\mathbf{p}<\mathbf{0 . 0 5}$ ). The difference between omeprazole and cimetidine was not appreciably affected by age, smoking, size of the ulcer and trial centre. Tolerability was similar in the two treatment groups. In the treatment of symptomatic gastric ulcer, omeprazole relieves the symptoms more quickly than cimetidine and heals a greater proportion of ulcers within four weeks.

Omeprazole specifically inhibits $\mathrm{H}^{\prime} \mathrm{K}$-ATPase, the 'proton pump' in the parietal cell' thereby effectively controlling gastric acid secretion.' Whilst $20 \mathrm{mg}$ om omeprazole has been shown to heal a greater proportion of duodenal ulcers within two and four weeks than $\mathrm{H}_{2}$-receptor antagonists, ${ }^{3}$ there have been fewer studies in patients with gastric ulcer. ${ }^{+5} \mathrm{One}^{+}$showed similar efficacy of omeprazole and ranitidine but included small ulcers which healed quickly on both regimens; two others ${ }^{\text {st }}$ showed that omeprazole 20$40 \mathrm{mg}$ healed gastric ulcers more quickly than ranitidine $150 \mathrm{mg}$ bd.

The present study was designed to compare omeprazole $20 \mathrm{mg}$ om with cimetidine $400 \mathrm{mg}$ bd on both the healing and the relief of symptoms of gastric ulcer. Particular attention was directed to the time course of the relief of symptoms with the two drugs.

Address for correspondence: Dr ('M Bate. Royal Alhert Edward lnfirmary. Wigan Lane. Wigan, 1 ancs WNI 2 NN

Accepted for publication 9 February $198 \%$.
Methods

TRIAI. DISIGN

The trial was a randomised double blind parallel group comparison of omeprazole $20 \mathrm{mg}$ om and cimetidine $400 \mathrm{mg}$ bd in 16 centres in the UK and the Republic of Ireland. Details of recruitment are given at the end of the paper: 13 centres were in the gastroenterology units of district hospitals and three involved local general practitioners in the treatment (but not endoscopic assessment) of patients. Blindness was maintained by the 'double dummy' technique: patients took either one active $20 \mathrm{mg}$ omeprazole capsule each morning and one placebo tablet morning and evening or one placebo capsule each morning and one $400 \mathrm{mg}$ cimetidine tablet morning and evening. At randomisation, patients were stratificd by age $(<65 ; \geq 65)$ and smoking (current smoker; non-smoker) for prospectively defined subgroup analyses; separate sets of drug packs were used for each of the four subgroups. 
Compliance was assessed by tablet counts, by enquiry by the physicians, and patients recorded each day on diary cards whether or not they had taken their tablets and capsules as directed.

Patients aged $18-80$ were eligible for the study if they had a symptomatic gastric ulcer $[\mathrm{GU}]$ confirmed by endoscopy within the three days prior to randomisation. Prepyloric ulcers were included and identified as such if the centre of the ulcer crater was within $3 \mathrm{~cm}$ of the pylorus. Uleer size was measured using biopsy forceps and at entry a minimum ulcer diameter of $5 \mathrm{~mm}$ was recommended.

Patients were excluded if they were pregnant, at risk of pregnancy, lactating, and if they had pyloric stenosis, oesophageal abnormalities, active gastrointestinal bleeding. previous surgery of the stomach or duodenum (or vagotomy), or severe concurrent disease. Other exclusions were the use of $\mathrm{H}_{2}$-receptor antagonists or other antisecretory drugs for more than two days in the two weeks before endoscopy and randomisation. the use of anticoagulants, theophylline, phenytoin or NSAIDs, and unwillingness to participate. The trial received ethical approval at each institution.

Symptoms were recorded (as mild, moderate or severe) by the physician at entry and after four weeks [26-30 days] and eight weeks [52-60) days: only if the ulcer was unhealed after four weeks] treatment. Endoscopy was repeated at these times and healing was defined as complete re-epithelialisation of all ulcer craters. Patients completed daily diary cards recording whether or not the trial medication was taken, the presence or absence of day and night pain, and the number of antacids taken [Rennies. Nicholas, were provided and taken prn].

Adverse events were elicited by response to an open question and by examination of the case record books. Blood and urine tests were performed at entry and at the patients final visits.

Biopsies were taken at the initial endoscopy, and if malignancy was detected but reported after randomisation the patients were withdrawn immediately: these patients are excluded from the efficacy analyses.

ANAIYYSI:S

Analyses of ulcer healing were carried out on an intention-to-treat basis where missing patients are assumed to be unhealed. Symptomatic data were analysed as the proportion of available patients at any particular time. The trial was designed to have a power of $80 \%$ to detect a $20 \%$ difference in healing rates at $\mathrm{p}<0.05$ if 190 patients completed the trial.

Differences in healing rates between the treatment groups were assessed using Mantel-Haenszel tests to take into account the stratification at randomisation. Symptomatic data recorded by enquiry at clinic visits were assessed using Wilcoxon's tests stratified for pretreatment symptoms. A multivariate logit analysis was conducted to estimate the influence of prognostic factors on healing rates. Differences in day pain. night pain and antacid consumption, recorded on diary cards over the first two weeks of the trial. between the two treatment groups were assessed using the Kolmogorov-Smirnov test. Data are expressed as means (SD) or with $95 \%$ confidence intervals $(C I)$ : $p$ values $>0.05$ are regarded as nonsignificant (ns).

\section{Results}

PATIENT CHARACTERISTICS

One hundred and ninety seven patients were randomised, 105 to receive omeprazole and 92 to receive cimetidine (29 and 21 respectively had prepyloric ulcers). In addition, one patient died after randomisation but before taking any trial medication and is excluded from all analyses. At randomisation, the groups were well balanced (Table 1). Patients were also comparable in the drugs that they were taking before and during the trial.

ENDOSCOPY AT ENTRY

Table 2 shows the number of gastric ulcers, the diameter of the "index ulcer" - the sole or largest ulcer $-(>5 \mathrm{~mm}$ in $94 \%$ of patients $)$ and other findings. The two treatment groups were comparable at entry.

PATIENTS ANAIYSED

Eight patients were withdrawn because of reports of malignancy, three from the omeprazole group and

Table 1 Patient characteristics at randomisation

\begin{tabular}{|c|c|c|}
\hline & ( meprasole & (imetidine' \\
\hline Paticnts (n) & 105 & 92 \\
\hline $\operatorname{Sex}(M: F)$ & $49: 56$ & $44: 48$ \\
\hline $\operatorname{Agc}(6,5: 6,5)$ & $71: 34$ & $58: 34$ \\
\hline $\operatorname{Agc}(y \mathrm{rs})$ & $57(14)$ & $57(1.3)$ \\
\hline Weight (kg) & $66(14)$ & $66(1.3)$ \\
\hline Height $(\mathrm{cm})$ & $165(9)$ & $16+(9)$ \\
\hline Smokers (yes:no) & $6.3: 42$ & $54: 38$ \\
\hline \multirow[t]{2}{*}{$\mathrm{BP}(\mathrm{mmHg})$} & $1.31(18)$ & $1.34(21)$ \\
\hline & $79(11)$ & $8(1)(12)$ \\
\hline HR (beats/min) & $76(9)$ & $79(8)$ \\
\hline Duration of ulcer symptoms (yrs) & $5.7(9.2)$ & $4 \cdot 7(K \cdot 8)$ \\
\hline $\begin{array}{l}\text { Duration of prosen ulcer discase } \\
\text { (yrs) }\end{array}$ & $1 \cdot 6(5 \cdot 4)$ & $1.5(4.5)$ \\
\hline $\begin{array}{l}\text { Duration of current symptomatic } \\
\text { episode ( } 1 \text { k) }\end{array}$ & $17(47)$ & $13(16)$ \\
\hline Episodes in last year (n) & $4 \cdot 2(7 \cdot 3)$ & $3 \cdot 1(5 \cdot 3)$ \\
\hline $\begin{array}{l}\text { Previous complications of ulcer } \\
\text { discase }\end{array}$ & 5 & 4 \\
\hline
\end{tabular}

Bleeding. melatena: data are shown as numbers of patients except where units are specified. I)ata expressed as means (SD). 
Table 2 Endoscopy findings at entry

\begin{tabular}{|c|c|c|}
\hline & $\begin{array}{l}\text { Omeprazole' } \\
\text { Patients }(n)\end{array}$ & $\begin{array}{l}\text { (imeridine' } \\
\text { Patients (n) }\end{array}$ \\
\hline \multicolumn{3}{|l|}{ Ulcers (n): } \\
\hline 1 & 82 & 7.3 \\
\hline 2 & 20 & 10 \\
\hline 3 & 1 & 5 \\
\hline 3 & 2 & 4 \\
\hline \multicolumn{3}{|c|}{ Size of index ulcer: } \\
\hline$<5 \mathrm{~mm}$ & 7 & 5 \\
\hline $5-10 \mathrm{~mm}$ & 67 & 59 \\
\hline $11-20 \mathrm{~mm}$ & 24 & 22 \\
\hline $20 \mathrm{~mm}$ & 5 & 3 \\
\hline unknown & 2 & 3 \\
\hline Hiatus hernia & 3 & 2 \\
\hline ()esophayitis & 3 & 1 \\
\hline Ciastritis & 3 & 6 \\
\hline Duodenitis & 5 & $s$ \\
\hline
\end{tabular}

five from the cimetidine group. The analyses are therefore carried out on 102 patients receiving omeprazole and 87 receiving cimetidine. After four weeks, data were available for $173(92 \%)$ patients and after eight weeks $169(89 \%)$.

UI.CER HEAI.ING - OVIERAI.I

After four weeks treatment, 74/102 (73\%) of the

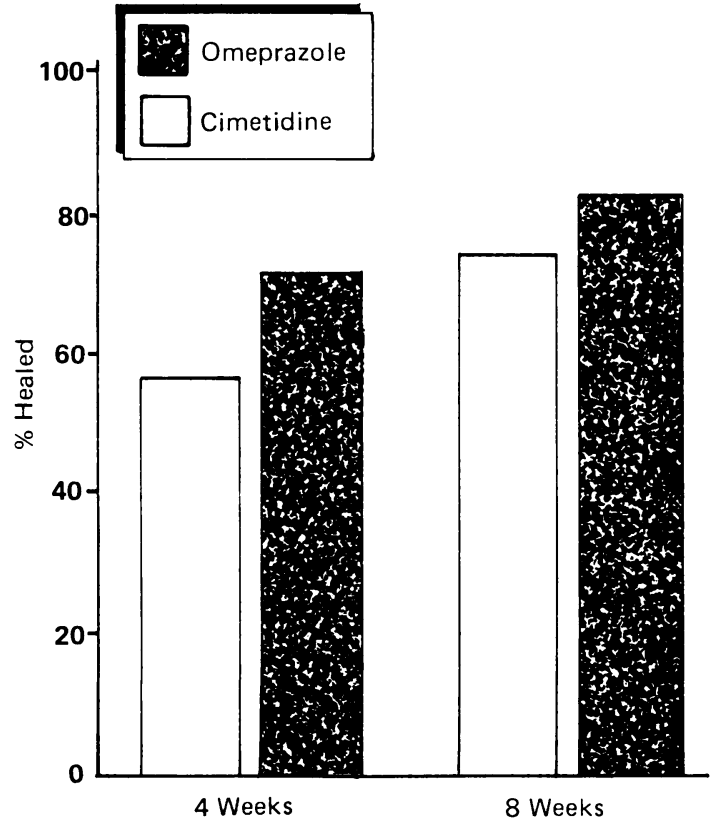

Fig. 1 Proportions of patients with gastric ulcers healed after four and eight weeks treatme'nt with cimetidine $+(0) \mathrm{mg}$ bd (open bars) or omeprazole 20) $\mathrm{mg}$ om (shaded hars). $p<0.0 .5$ at four weeks. patients receiving omeprazole had healed uleers compared with $50 / 87(58 \%: \mathrm{p}<0.05)$ of those receiving cimetidine (Fig. 1). The therapeutic gain, or difference between the percentages of patients healed, is $15 \%(\mathrm{CI}+110+29 \%)$. The corresponding cumulative figures after eight weeks were $86 / 1012$ $(84 \%)$ and $65 / 87(75 \%: p=() \cdot 1)$ with a therapeutic gain of $9 \%(\mathrm{CI}-2$ to $+21 \%)$.
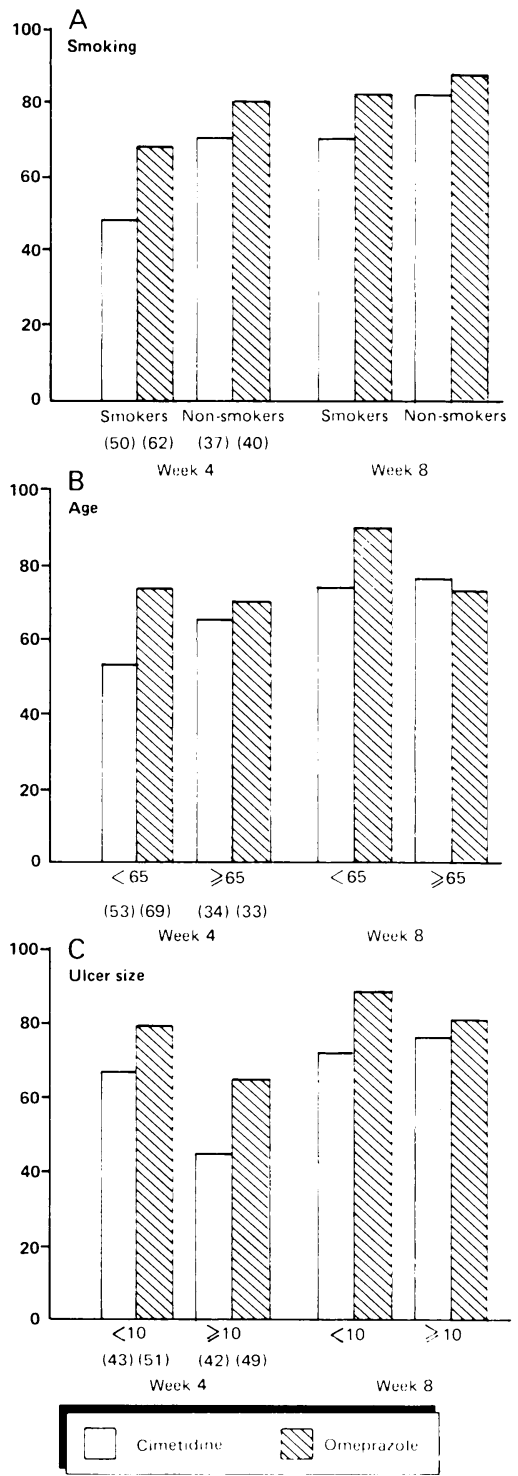

Fig. 2 Healing rates in subgroups prospectively defined and stratified for smoking and age. and for patie'nts with index ule er sizes above and below the median of $\mathrm{l}(0 \mathrm{~mm}$.

Presentation as in Figure l. Numbers in parentheses are the number of patients in each subgroup). 
LICER HEALING - SLBBROL'PS

\section{Smoking}

Overall smokers had a smaller proportion of ulcers healed at four $(p<0 \cdot(0.5)$ and eight (ns) weeks than non-smokers. In each subgroup the proportion of ulcers healed in patients receiving omeprazole was greater than in those receiving cimetidine (Fig. 2a).

Age

Age did not affect overall healing rates significantly. Generally the healing rates were higher in the omeprazole than cimetidine groups (Fig. 2b).

\section{Ulcer size}

Groups were formed retrospectively for those with an index ulcer under the median diameter of $10 \mathrm{~mm}$ and those $\geq 10 \mathrm{~mm}$. A greater proportion of ulcers in the group with smaller ulcers healed after four weeks $(p<0.05)$ than those in the group with larger ulcers. In each subgroup, a greater proportion of the ulcers treated with omeprazole healed compared with those treated with cimetidine (Fig. 2c).

UI.CFR HEAIING - PROGNOSTIC FACTORS

In an initial logit analysis, alcohol consumption. sex. number of ulcers, history of ulcer disease and number of episodes of ulcer symptoms had no prognostic effect on healing. In the final model. treatment (omeprazole or cimetidine) had a significant prognostic effect as did ulcer size and smoking. notably after four but not eight weeks. Trial centre and age

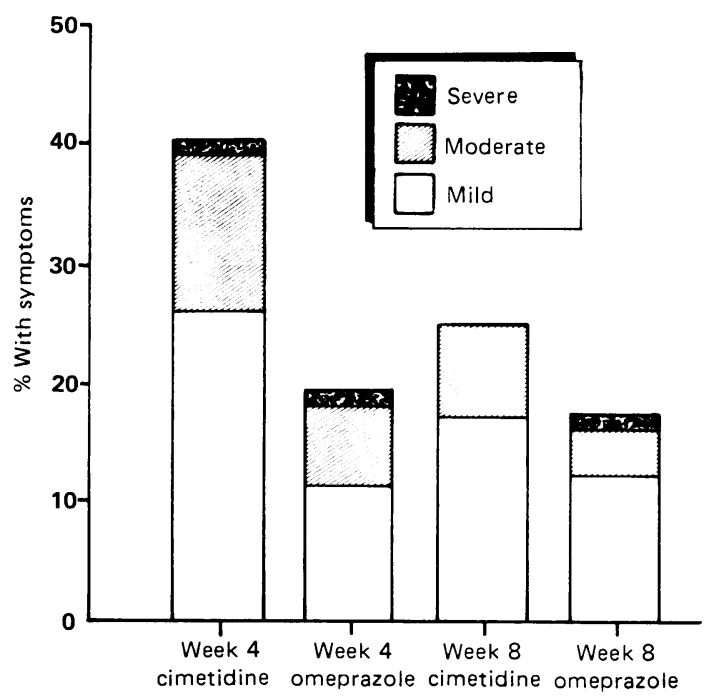

Fig. 3 Proportion of patients reporting pain of varying severity at clinic visits. At entry, $19^{\circ}$ ", in each group had mild pain. $45 \%$ moderate and $35 \%$ serere pain. did not significantly affect the prognosis for GU healing.

PREPYI.ORIC UI.CHES

Healing rates for prepyloric ulcers were similar to the whole group: at four weeks, $11 / 19(58 \%)$ treated with cimetidine and 22/28 (79\%) with omeprazole had healed. The corresponding figures for corporeal ulcers were $57 \%$ and $70 \%$ respectively.

SYMPTOMS - CIIINIC VISITS

At entry, all but two patients reported symptoms. After four weeks, $81 \%$ of patients receiving omeprazole reported no symptoms compared with $60 \%$ receiving cimetidine $(\mathrm{p}<\mathbf{0 \cdot ( ) 1 )}$. After eight weeks, the difference (Fig. 3) was no longer significant.

Patients were questioned about specific symptoms at clinic visits. After four but not cight weeks, those in the omeprazole group reported less daytime pain and heartburn $(\mathrm{p}<0 .(05)$ than those in the cimctidine group. There was no difference in nocturnal pain or nausea. Too few patients suffered vomiting, haematemesis, melaena or other symptoms for meaningful analysis.

SYMPTOMS - DIARY CARDS

After four weeks (Fig. 3) the majority of patients did did not experience pain on either regimen. Complete diary card data available from $8(-83 \%$ of randomised patients in each group, however, reveal that from days 2 to 14 inclusive fewer patients in the omeprazole group than the cimetidine group had day pain (Fig. 4, left panel: $\mathrm{p}<() \cdot() 1)$, or night pain (Fig. 4, right panel: $p<(0.05)$, and patients in the omeprazole group took fewer antacids $(\mathrm{p}<0 \cdot(0)(0) 1)$.

In a stricter analysis of patients whose symptoms disappeared, defined as patients without pain who took no antacids, a greater proportion of those receiving omeprazole than cimetidine had relief of symptoms (Fig. 5: $\mathrm{p}<() \cdot()() 1)$.

SAFETY

In the omeprazole group, $19 / 102(19 \%)$ and in the cimetidine group $13 / 87$ (15\%) patients had adverse experiences. Two adverse experiences were classified as serious, both in the omeprazole group; neither was regarded as drug related (one left ventricular failure (LVF) presumed secondary to ischaemic heart disease, and one with LVF treated before the trial, a urinary tract infection and dehydration, nausea, dyspnoea, and vomiting). Seven more patients (four in the omeprazole group: two of these complained of persisting ulcer symptoms and were included as adverse experiences in this study) withdrew because of adverse events. Table 3 gives details of the adverse events by system. No excess of out-of-range values in 

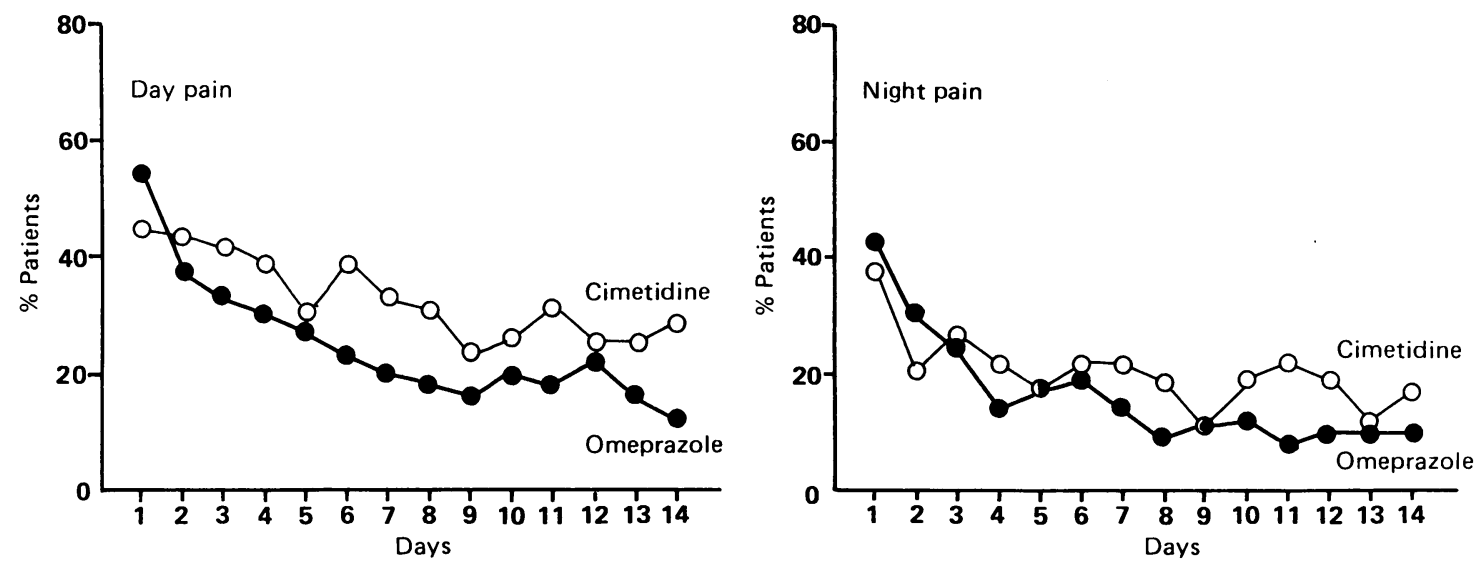

Fig. 4 Proportion of patients reporting day and night pain during the first two weeks of omeprazoie or cimetidine treatment.

either group was detected by analysis of blood taken at the start and end of treatment (the measurements were: haemoglobin, haematocrit, WBC, platelets, creatinine, bilirubin, alkaline phosphatase, ALAT, ASAT, sodium, potassium, calcium) or by urine tests (glucose, protein).

\section{Discussion}

Previous reports of the effects of omeprazole on gastric ulcers have concentrated on endoscopic assessments ${ }^{+5}$ and have shown that omeprazole $20 \mathrm{mg}$

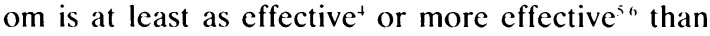
ranitidine. The present study shows that this dose of omeprazole, ${ }^{27}$ which does not cause complete $24 \mathrm{~h}$ suppression of gastric acid secretion in voluntecrs, not only heals a greater proportion of gastric ulcers than cimetidine over a four week period, but also

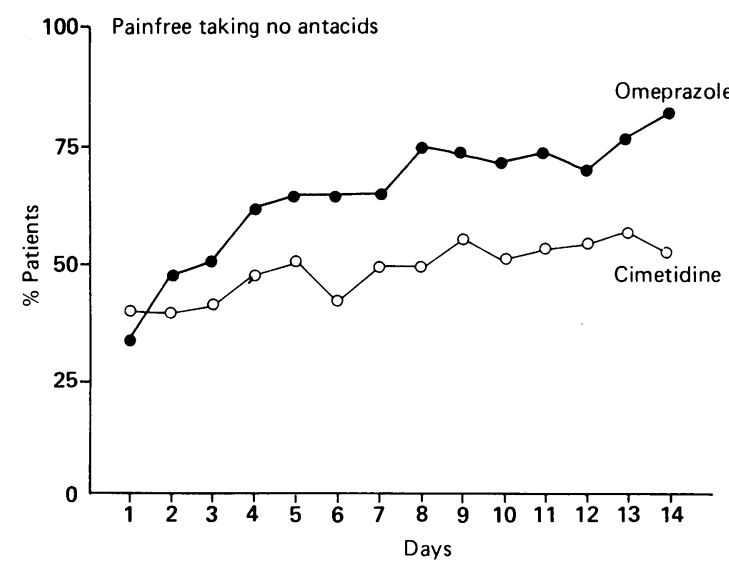

Fig. 5 Proportion of patients who were both free of pain and did not take any antacids during the first two weeks of treatment. relieves the symptoms more rapidly. We are confident in the symptomatic findings because both clinic questions and diary cards gave consistent information, diary cards were completed accurately by over $80 \%$ of patients in both treatment groups, and the differences between omeprazole and cimetidine are consistent in terms of both pain relief and antacid consumption.

More rapid healing of gastric ulcers occurred in all subgroups treated with omeprazole than those receiving cimetidine. The prospective stratification for age and smoking resulted in comparable numbers of patients treated with each drug in the subgroups. Age did not seem to affect healing rates consistently, but fewer smokers, especially in the cimetidine group, healed within four weeks than non-smokers. After eight weeks, the rate of ulcer healing with cimetidine was similar to that with omeprazole after four weeks. As might be expected, the smaller ulcers tended to heal more rapidly than larger ulcers on

Table 3 Summary of adverse events

\begin{tabular}{lll}
\hline System & Omeprazole & Cimctidine \\
\hline CNS & 7 & 3 \\
Endocrine & 0 & 1 \\
Circulatory & 1 & 0 \\
Gi: & & \\
$\quad$ pain & 4 & 0 \\
$\quad$ vomiting & 2 & 1 \\
$\quad$ diarrhoca & 5 & 3 \\
$\quad$ constipation & 0 & 2 \\
Urinary & 0 & 2 \\
Musculoskeletal & 1 & 1 \\
Skin rashes & 0 & 2 \\
Respiratory & 1 & 0 \\
\hline
\end{tabular}

Within each category, such as CNS, there was a mixture of symptoms. Adverse events, such as GI pain. include comments made in the record books as well as responses by patients to questions. 
both treatments but even in the patients with large ulcers, omeprazole healed $65 \%$ within four weeks ( cimetidine $=45 \%$ ). In this study prepyloric ulcers behaved in much the same way as corporeal ulcers and did not exhibit the very high healing rates seen in another study," although the numbers of patients with prepyloric ulcers in the present study was too small to make firm conclusions.

After eight weeks' treatment, the differences between the two drugs became smaller, as would be expected, and this trend was seen in all subgroups. A minimum of eight weeks' treatment with cimetidine has been proposed for treating gastric ulcer with continuation to 16 weeks if necessary." In contrast, four weeks' treatment with $20 \mathrm{mg}$ omeprazole once daily results in gastric ulcer healing rates of $700^{\circ}-80^{+\%} \%$. Omeprazole and cimetidine were similarly well tolerated.

The results of the present trial support the view that a correlation may exist between the control of acid secretion and the healing of gastric ulcers." It seems likely that there is enhanced control of acid secretion with omeprazole which results not only in faster healing of the ulcer crater but also in more rapid symptom relicf.

Patients were recruited by the following physicians: C M Bate (36), S P Wilkinson (24), G V H Bradby (24), M C Bateson (21), W S Hislop (18), J P Crowe (12), C P Willoughby (10), the Department of General Practice at Glasgow (Prof J H Barber, Dr G P Crean, 11), M B Mclllmurray (Lancaster, 9), the Department of General Practice at St George's, London (Prof P Freeling, Dr T C Northficld, 8), Dr R W Crofton (Carluke, 6), Dr M O Rake (Canterbury, 6), Dr M J Dew (Llanelli, 5), the Department of General Practice at Cardiff (Prof R Harvard Davis, Prof N C H Stott, Dr P M Smith, Dr B W Lawric, 4), Dr R H Teague (Torquay, 2), and Dr P G Wheeler (Ashford, 2).
Miss Alison Scrimgeour analysed the trial and Miss Pam Soan prepared the manuscript.

\section{References}

I Fellenius E. Berglindh T. Sachs G, et al. Substituted benzimidazoles inhibit gastric acid secretion by blocking $(\mathrm{H}+. \mathrm{K}+)$ ATPase. Nature 1981: 290: 159-61.

2 Lind T. Cederberg C. Ekenved G, Haglund K. Olbe L. Effect of omeprazole - a gastric proton pump inhibitor on pentagastrin stimulated acid secretion in man. (illt 1983: 24: 270-6.

3 Bardhan KD, Bianchi Porro G, Bose K. et al. A comparison of two different doses of omeprazole versus ranitidine in treatment of duodenal uleers. $J$ Clin Gastroenterol 1986: 8: 408-13.

4 Classen M. Dammann H-G. Domschke W, e't al. Omeprazole heals duodenal but not gastric uleers more rapidly than ranitidine. Hepatogastroenterology 198.5 ; 32: $24.3-5$.

5 Walan A. Bader JP. Classen M, et al. Effect of omeprazole and ranitidine on ulcer healing and relapse rates in patients with benign gastric ulcer. $N$ Engl J Med 1989: 320: $69-75$.

6 Barbara L. Saggioro A, Olsson J, Cisternino M, Franceschi M. Omeprazole $20 \mathrm{mg}$ om and ranitidine 150 $\mathrm{mg}$ bd in the healing of benign gastric ulcers [Abstract]. Gut 1987: 28: A 1341 .

7 Sharma BK. Walt RP. Pounder RE. Gomes MdeFA. Wood EC, Logan LH. Optimal dose of oral omeprazole for maximal 24 hour decrease of intragastric acidity. (iut 1984: 25: 957-64.

8 Lauritsen K. Rune SJ, Wulff HR, et al. Effect of omeprazole and cimetidine on prepyloric gastric ulcer: double blind comparative trial. Gut 1988: 29: 24953.

9 Graham DY, Akdamar K. Dyck WP. et al. Healing of benign gastric ulcer: comparison of cimetidine and placebo in the United States. Ann Intern Med 1985; 102: 57.-6.

10 Howden CW. Jones DB. Peace KE. Burget DW. Hunt $\mathrm{RH}$. The treatment of gastric ulcer with antisecretory drugs: relationship of pharmacological effect to healing rate. Dig Dis. Sci 1988: 33: 619-24. 